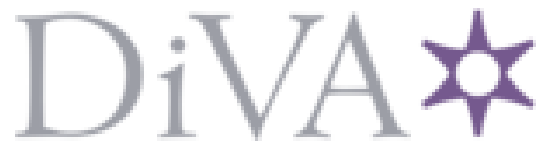

http://www.diva-portal.org

Preprint

This is the submitted version of a paper presented at CVMP '19: European Conference on Visual Media Production.

Citation for the original published paper:

Ardal, D., Alexandersson, S., Lempert, M., Abelho Pereira, A T. (2019)

A Collaborative Previsualization Tool for Filmmaking in Virtual Reality

In: ACM Digital Library

N.B. When citing this work, cite the original published paper.

Permanent link to this version:

http://urn.kb.se/resolve?urn=urn:nbn:se:kth:diva-267229 


\section{A Collaborative Previsualization Tool for Filmmaking in Virtual Reality}

\author{
Dui Ardal \\ dui@kth.se \\ Royal Institute of Technology \\ Stockholm, Sweden \\ Mirko Lempert \\ mirko.lempert@uniarts.se \\ Stockholm Academy of Dramatic Arts \\ Stockholm, Sweden
}

\author{
Simon Alexandersson \\ simonal@kth.se \\ Royal Institute of Technology \\ Stockholm, Sweden \\ André Tiago Abelho Pereira \\ atap@kth.se \\ Royal Institute of Technology \\ Stockholm, Sweden
}
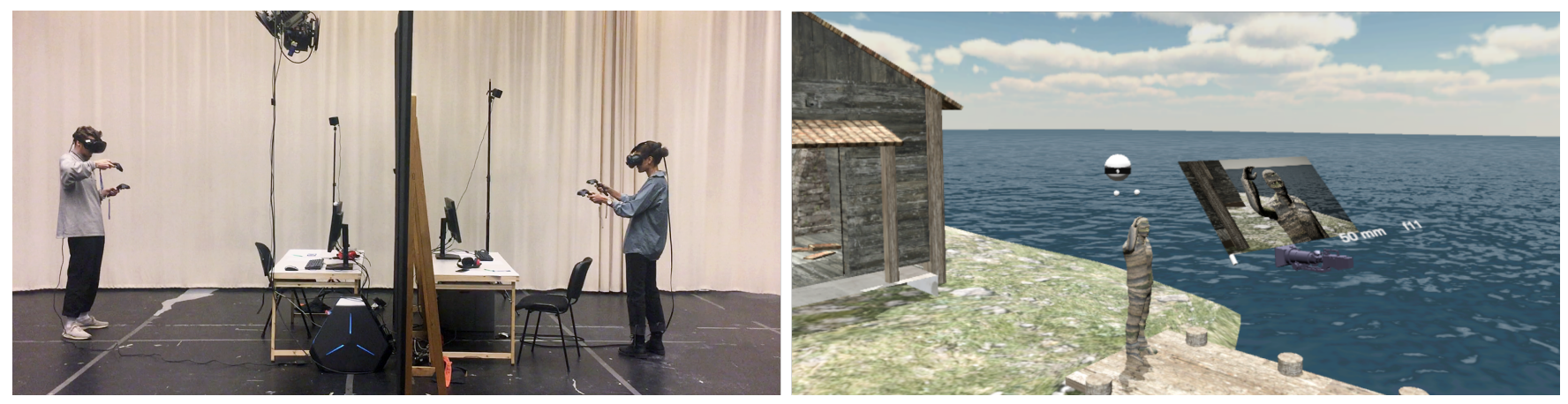

Figure 1: Two participants performing a collaborative previs session (left); a screenshot of a participant's interface (right).

\begin{abstract}
Previsualization is a process within pre-production of filmmaking where filmmakers can visually plan specific scenes with camera works, lighting, character movements, etc. The costs of computer graphics-based effects are substantial within film production. Using previsualization, these scenes can be planned in detail to reduce the amount of work put on effects in the later production phase. We develop and assess a prototype for previsualization in virtual reality for collaborative purposes where multiple filmmakers can be present in a virtual environment to share a creative work experience, remotely. By performing a within-group study on 20 filmmakers, our findings show that the use of virtual reality for distributed, collaborative previsualization processes is useful for real-life preproduction purposes.
\end{abstract}

\section{CCS CONCEPTS}

- Human-centered computing $\rightarrow$ Interface design prototyping; Collaborative content creation.

Permission to make digital or hard copies of all or part of this work for personal or classroom use is granted without fee provided that copies are not made or distributed for profit or commercial advantage and that copies bear this notice and the full citation on the first page. Copyrights for components of this work owned by others than the author(s) must be honored. Abstracting with credit is permitted. To copy otherwise, or republish, to post on servers or to redistribute to lists, requires prior specific permission and/or a fee. Request permissions from permissions@acm.org.

CVMP '19, December 17-18, 2019, London, United Kingdom

(c) 2019 Copyright held by the owner/author(s). Publication rights licensed to ACM. ACM ISBN 978-1-4503-7003-5/19/12 ..\$15.00

https://doi.org/10.1145/3359998.3369404

\section{KEYWORDS}

Virtual reality (VR); collaborative virtual space; film-production; distributed workspaces; previsualization

\section{ACM Reference Format:}

Dui Ardal, Simon Alexandersson, Mirko Lempert, and André Tiago Abelho Pereira. 2019. A Collaborative Previsualization Tool for Filmmaking in Virtual Reality. In European Conference on Visual Media Production (CVMP '19), December 17-18, 2019, London, United Kingdom. ACM, New York, NY, USA, 10 pages. https://doi.org/10.1145/3359998.3369404

\section{INTRODUCTION}

Previsualization (previs) is a collaborative process of planning scenes and shots within the pre-production stages of filmmaking. Traditionally, this process has been performed with drawings, concept images, sketches, etc. [Janson 2019], and it is not until recently that previs has been performed with $3 \mathrm{D}$ animation tools and software. The use of computer graphics-based (CG) technologies for providing visual effects within filmmaking is a well-established practice. However, the costs of these technologies are substantial, therefore it is important to carefully plan shots that require the expertise of CG professionals [Honthaner 2017]. With recent advancements in Virtual Reality (VR) technologies, the film industry sees a shift where planning for different scenes and takes can be done in a more immersive and tangible way. VR enables a user to be present in virtual environments resembling specific locations, and thus may help filmmakers to work creatively in a familiar setting. Furthermore, remote work is becoming increasingly common in 
the film industry and VR can be the ideal solution to foster collaboration within these settings. The advantage of using online multi-user VR is that it may enable a sense of being transported to real environments where co-workers can socially immerse with their colleagues. Remote collaborative previs may thus not only be an important tool for creativity and communication, but also for saving the time, expenses and environmental costs of travelling.

The main research question addressed in this paper is: How useful and familiar can VR technologies be for remote collaboration in previsualization?

To research this topic, we describe and evaluate a tool that provides an immersive and collaborative previs environment where filmmakers can create, discuss and validate different takes, shots and entire scenes. The tool features a VR interface where the intended users do not need advanced computer literacy to understand and master the functionalities. A within-subjects experiment was conducted, where the participants (professional filmmakers, primarily from the Stockholm Academy of Dramatic Arts) performed previs sessions in the proposed collaborative setup and in a control solo setup. In this paper, we analyze the results from our experiments to assess the impact of, and provide design insights on, remote collaborative VR technology that enables previsualization of film scenes.

\section{RELATED WORK}

In face-to-face interaction, communication can be achieved in a delay-free and multi-functional way, as is explained in [Clark and Brennan 2004], where Clark and Brennan claim that grounding, i.e. finding common ground, is important for how communication works effectively. Thus, the costs of constraints of mediums can affect formulation, production, and understanding. Collaboration calls for similar grounding as for general communication in order to work effectively. The importance of shared visual space, mental models, context, and speech is evident in earlier research [Carroll et al. 2006; Fussell et al. 2000; Gergle 2005; Gergle et al. 2005; Shakeri et al. 2017], where the context and understanding of how to collaborate and what to collaborate on can be made clear. In [Fussell et al. 2000], Fussel, et al., accounts for four types of visual information that is important for grounding in collaborative contexts: participants' heads and faces, participants' bodies and actions, shared task objects, and shared work context. Similarly, having a shared visual space in collaborative work environments makes participants' more likely to let their actions speak for themselves instead of having to explain verbally, simultaneously [Clark and Brennan 2004; Gergle et al. 2005].

Technological solutions for remote collaboration have taken many different forms. From letters, telephone, video-conference systems to more advanced forms of technology that are now starting to show potential for creating efficient and natural forms of collaboration [Celata et al. 2018; Fussell et al. 2003; Johnson et al. 2015; Khan et al. 2016; Piumsomboon et al. 2016]. However, most of these authors also claim that the lack of developed technology can hinder good collaboration. Poor field-of-vision in interfaces and lack of asymmetry in controls are two examples of how the design of technical solutions could have been standing in the way of usable interfaces for interactive collaboration [Bateman et al.
2015]. This is something that VR technologies can be better suited for, as the immersive qualities of virtual headsets and its controls are extensive enough to facilitate grounding in collaborative environments. Advances in VR technologies has led to decreased prices and a more widespread usage of the technology [Feltham 2018; Ladwig and Geiger 2018; Perry 2015], which might represent clear opportunities for remote collaboration purposes. VR can be seen as a way of achieving near perfect co-presence with other people [Perry 2015]. Co-presence is an especially important aspect for attaining grounding in virtual 3D environments [Gergle et al. 2005; Ramsbottom 2015]. However, there are still problems with VR that prevents the medium of fully delivering on the promise of full copresence. In [Anthes et al. 2016], Anthes et al., raises a number of issues on the state of VR technologies. It is clear that representation of users is still a problem as a result of lack of information on facial expressions, eye-gazing, and body movement. Nevertheless, recent advancements are attempting to tackle these problems with the use of eye-tracking inside VR headsets, gloves that can represent fingers, etc. Thus, user representation is likely to improve in the near future [Ladwig and Geiger 2018; Pfeil et al. 2018]. As such, the affordances of elements in a VR environment needs to be carefully decided upon, when designing for VR. In [Ellis 1995], Ellis makes clear that affordances in VR should mimic the real world as much as possible, as the affordances of real artifacts are expected to have the same affordances in the virtual environment. Furthermore, in the virtual environment, extended affordances can be developed, as the virtual environment can in its nature facilitate this [Ellis 1995].

In this paper, we focus on designing collaborative VR technologies that enable previsualization, a pre-production stage within filmmaking. Previsualization is a process where filmmakers create visual prototypes of scenes in a film that are otherwise difficult to visualize. Different use-cases are e.g. scenes with visual effects, expensive set constructions or digital set extensions. While hand-drawn floor plans and storyboards are still the dominating previsualization technique within creatives, high-budget productions commonly make 3D animated visualizations of the film, predominantly using $3 \mathrm{D}$ modelling and animation software such as Autodesk Maya ${ }^{1}$ or Blender ${ }^{2}$. However, this process is not only time consuming and costly, it also delegates creative control over the previs to external animators. The possibilities to use real-time technologies such as game engines to provide more interactive and user friendly interfaces have been attempted before. The main promise of such technology is the ability for the creative team of a film-production to create the previs by themselves. In the work by [Nitsche 2009], a previs system was implemented using Unreal engine together with various custom built input devices for puppeteering characters and camera. The study argues that animation and camera control are the most important areas for previs. Several other studies [Ichikari et al. 2007; Mori et al. 2011; Spielmann et al. 2016; Tenmoku, R. and Ichikari, R. and Shibata, F. and Kimura, A. and Tamura 2006] have explored Mixed Reality (MR) interfaces for previs. These interfaces are however restricted to camera work (although [Spielmann et al. 2016] has basic key-framing functionality), and and thus does not

\footnotetext{
${ }^{1}$ https://www.autodesk.com/products/maya/overview

${ }^{2}$ https://www.blender.org/
} 
exploit the possibilities to previsualize character movements in real time.

In [Ramsbottom 2015], a VR previs system is presented where the user can create low resolution animations by adding and editing key frames on a timeline. The system used a rotation sensing headset (Oculus DK2) and a game pad for input, which limits the immersion and familiar interaction mechanisms included in later hardware. The system closest to ours is presented in [Muender 2018]. By evaluating their system on 6 expert users from film and theater (surprisingly none being a director or photographer), they found that their tool was practical for real-world applications. Like us, Muender et al., uses room scale VR with positional tracking, and a miniature approach where the users move scale models and cameras. Unlike us, they only create snapshot still-images of stiff characters, and they do not use a collaborative setting. We will contribute to the state-of-the-art in this field by performing a larger study with a greater number of film professionals, and by investigating the usefulness of distributed collaborative previs in VR.

\section{PREVIS VIRTUAL REALITY INTERFACE}

In this section, we present the interaction design and the user interface employed in the study. The implementation builds on a system by Monocular ${ }^{3}$, which has previously been in used in several feature film and TV-series productions. The system is designed for early conceptual Previs for mid- to high budget feature films and TVseries, and is intended to be used directly by a creative team (director, photographer and scenographer), without any prior knowledge of 3D technology or animation. For this study, we extended the system with networking and voice chatting capabilities for multiuser VR, as well as a specifically designed asymmetric user interface described below. To facilitate fast learning of the tool, we removed some functionality not necessary for the study.

The system is built in the Unity3D game engine and uses the HTC Vive Pro VR system with room-scale setup and two handcontrollers. This allows for six degrees-of-freedom (DOF) input control in a tracking area of about $7 \mathrm{~m} \times 7 \mathrm{~m}$.

\subsection{System overview}

Creating visualizations in the system is divided into three phases: scene preparation, realtime animation and video export. The scene preparation phase is considered to be an offline editing phase, and uses the built-in editing tools in Unity. In this phase a specialized artist creates and assembles different 3D models to build up a virtual mock-up of the set. The 3D models typically originates from scenography models made by the art department, 3D scans of realworld locations or 3D models downloaded from online repositories. Rigged character models can be generated from a multitude of software packages. As this process is similar to many types of applications within games and visualization, we will not discuss it further in this paper. The realtime animation phase, however, is considered to be online, and simulate the action taking place on a real-world film set. This includes all action taking place in front of the camera, such as character movements and dialogue, as well as camera motion and the changing of optics (focal length and aperture). After animation is completed, the recorded camera shots

\footnotetext{
${ }^{3}$ http://monocular.se
}

are exported to video format in the video export phase. Listed below are some design choices that are specific for the system:

- No keyframing: All animations are created in real-time by processing the 6 DoF tracking data from the controllers to characters and cameras, and recording the resulting motion data.

- Miniature paradigm: We adopt a miniature paradigm where the users puppeteer scale models of the characters and cameras. In contrast to using a full-blown motion capture studio, this design enables a much simpler and less costly setup. Using small scale models, the space of action in the scene can be increased, and the system can simulate a wide range of shots such as dolly, crane and helicopter shots, as well as an increased range of character movement. Our approach is similar in spirit to the early Previs made for the "speeder bike" sequences of Star Wars episode VI ${ }^{4}$, where the sequence was filmed with action figures in a miniature set. However, our digital representation allows adding procedurally generated walk cycles to character motion, and for puppeteering the head and hands of a character, see Figure 2. These features have proven to produce expressive and readable character motion sufficient for understanding the basic actions and intentions of the characters.

- Incremental animation passes: The user incrementally records first each character's motion, and then each camera. When recording each object, previously recorded animations on other objects are played back in real time. This allows for the incremental buildup of complex scenes including dozens of characters and extras.

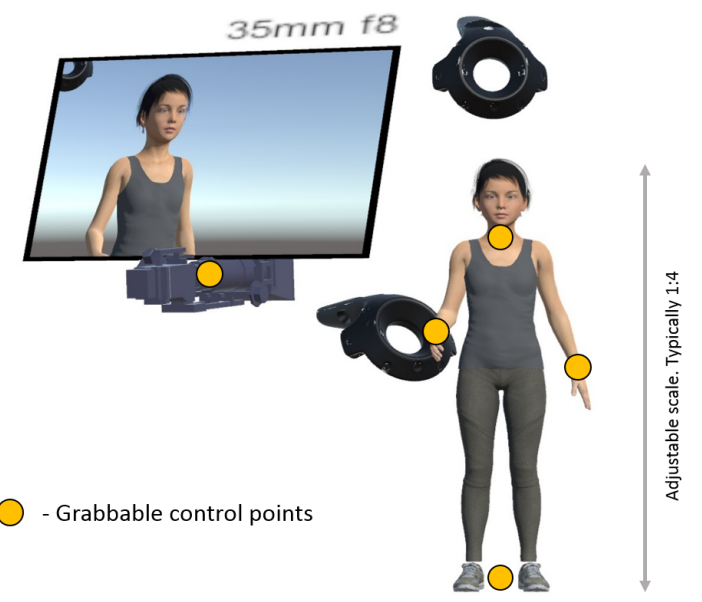

Figure 2: Puppeteering scale models of characters and cameras.

${ }^{4}$ From 'Star Wars' to 'Jedi': The Making of a Saga. TV documentary (1983) 


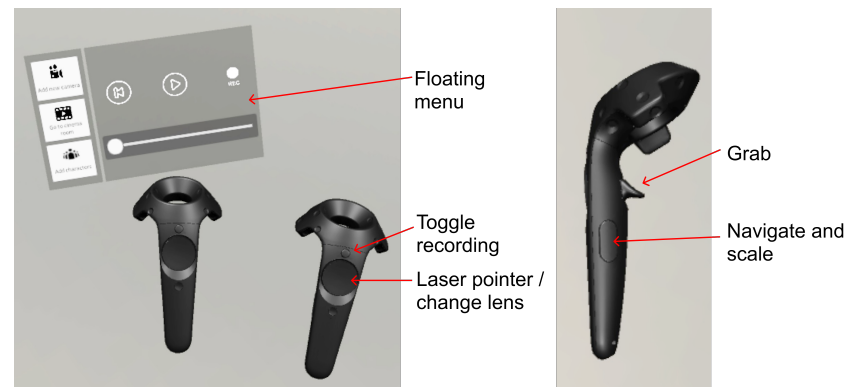

Figure 3: Floating user interface and controls.

\subsection{User interface and controls}

The user interface consists of a menu floating over the left controller, and different actions linked to the buttons and touch pads of the two controllers (see Figure 3).

3.2.1 Navigation. Navigation and scaling is controlled by the grip buttons. As we use a miniature setup, we found that navigation by moving the virtual environment was more intuitive than the standard teleportation mechanism common to VR applications. Pressing one grip button while moving the controller moves the virtual world. Pressing both grip buttons while increasing/decreasing the distance between the controllers, scales the virtual environment up/down.

3.2.2 Laser pointer. Pressing the right touchpad starts a laser pointer used for referencing (e.g. showing other users where to look) or interacting with the left-hand menu.

3.2.3 Spawning characters and cameras. Spawning characters and cameras is done through the left hand menu. When a user clicks the "Add new character" or "Add new camera" buttons, a new character or camera is spawned in front of the user.

3.2.4 Animating characters. Characters are manipulated by grabbing control points placed on the models with either of the trigger buttons (Figure 2). There is one root control point located between the feet, and additional ones at the head and hands. When the root control is grabbed, the character's locomotion (standing, walking or running) is procedurally generated according to the speed and direction of the controller. The head and hand controls specify head look direction and arm pose by using inverse kinematics. Characters can optionally be snapped to the ground, and thus follows the height of the ground.

3.2.5 Animating cameras. Cameras have control points located at the center of the model. When grabbing a camera, a touchpad menu appears where the user can change the focal length and aperture size. All cameras have a screen attached to the top, providing visual feedback of the camera view.

3.2.6 Timeline control. The timeline is located in the left-hand menu, and contains traditional buttons for rewinding, playback and recording, as well as a slider for scrubbing the time. Recording can also be toggled by pressing the right application button This is especially useful when both controllers are occupied for puppeteering.
3.2.7 Motion editing. Previous recordings can be edited by scrubbing the time line to a desired location, selecting a camera or character and starting a new recording from that point in time. The new recording will be merged with the old one, overriding it with a small cross fade period.

3.2.8 Cinema room. The cinema room is an empty room with a big screen, where the user can see the view of all cameras in the scene. The cinema room also has the interactable timeline, play-button and rewind timeline-button. The cinema room was created to show the participants a joint visualization of the recorded cameras, providing a room for discussion.

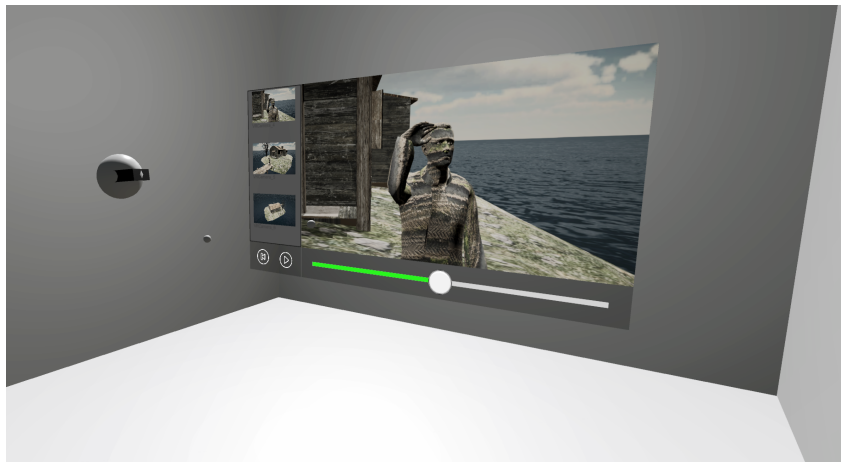

Figure 4: Cinema room.

3.2.9 Asymmetric user interface. It has been shown that by making use of specialized roles, as well as the knowledge-in-common of participants, collaboration can turn out to be more effective [Carroll et al. 2006; Johnson et al. 2015]. As such, similarly to [Elvezio et al. 2018], we adopt an asymmetric user interface where we emphasize how certain users can be specialized in certain tasks. In previs, each user will embody a role common within previsualization teams. Each role has different functionalities that are accessed by assymetric floating menus/interfaces. This workflow provides users with a more familiar work distribution, but also avoids double command, such as two users simultaneously attempting to start recording with the same camera. Although Monocular's original software allows for representing three of the main creative roles in film making (director, photographer and scenographer), we limit the design of the tool in this project to two different participants/roles. We assume that a set design is already in place from the preparation phase and we decided to focus on studying the collaboration between directors and photographers. As in a real-world scenario, the director is responsible for guidance and direction of the actors, and the photographer for handling the camera. We designed the director role in the system to be mainly in charge of character animation and reviewing the camera work in the cinema room, while the photographer role was designed to handle the camera control and timeline. Thus, we confined the menu for the director role to only have the options for spawning characters/cameras and teleporting to the cinema room, and the photographer role to additionally control the timeline and recording. The menus for the different roles are shown in Figure 5. 

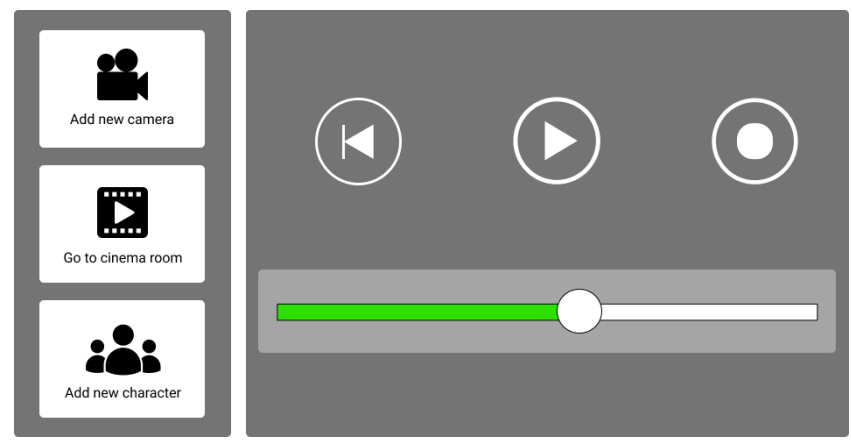

Figure 5: Asymmetric interface. The director can only access the left sidebar menu.

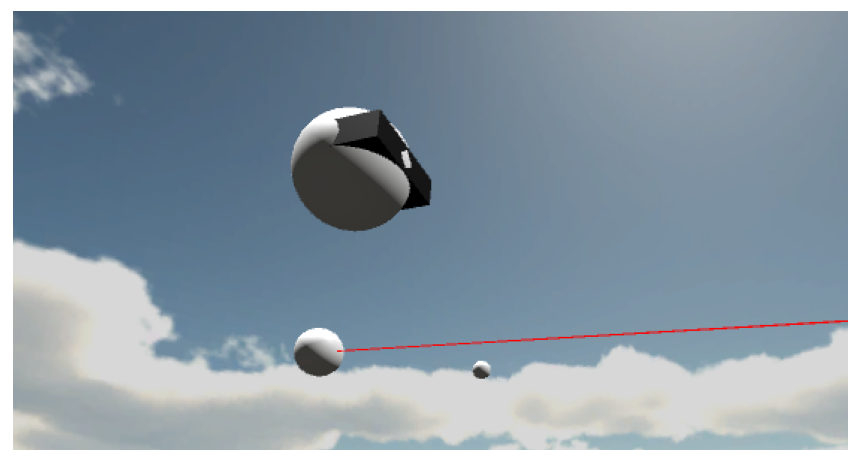

Figure 6: Participant referencing with laser pointer.

3.2.10 Multi-user interface. To visualize the other users engaged in the interaction, we use a simple representation consisting of spheres located at the head and hands (Figure 6). The head sphere has a box attached representing the HMD, giving a visual cue to the look direction. The right hand can send out a laser pointer for referencing. This simple representation was deemed enough for the interactions in the experiment, especially since the communication revolves around the visuals of the scene and the study is restricted to two-party collaboration (where gaze is of lesser relevance to disambiguate participants' attentional focus).

\section{EVALUATING PREVIS WITH FILM EXPERTS}

To measure the usefulness and familiarity effects of collaborative work in the virtual environment proposed above, an experiment on the intended user segment was performed for evaluating the system.

\subsection{Participants}

For the experiment, 20 participants were recruited. The participants were all specialists. One person had been active in the film industry for 1-2 years, one person for 2-3 years, four persons for 3-5 years, seven persons for 5-10 years and seven people for more than 10 years. The ages differed between 18-59 years, with 10 female, 8 male, and 2 who preferred not to disclose.

\subsection{Manipulation}

The evaluation was based on a within-subjects study in which participants conducted a previs session in two different settings: one in the proposed collaborative condition and one in a control solo condition. As a control condition, a modified version of our collaborative interface allowed participants to perform the combined actions of the roles chosen in our collaborative condition. The control condition is therefore similar to our initial starting point (the tool offered by Monocular) and keeps most interface elements between conditions constant for accomplishing a controlled comparison.

\subsection{Tasks and order}

Two different tasks/sub-scenes with two different scripts are used for this experiment. The sub-scenes used in the evaluation were taken from the pre-production of an actual animated short-movie: Home in the Distance by Andreas Dahn (in development). By letting that material be used for this experiment, a real-world scenario with both a virtual environment and script for a final scene existed and two different tasks/sub-scenes could be derived from those assets. The story takes place in a small house on a remote island where a solitary man plays the main character. We minimized order effects and bias from having performed the study in a specific order by making participants try out each of the settings in different orders. The reason for choosing a within-subjects study design was to minimize individual differences and obtain direct subjective feedback about differences in conditions.

\subsection{Procedure}

Before each previs session, the participants performed a training session supervised by an experimenter. The training was divided into two parts: the first part included a showcase of the tool, its controls and functions. Afterwards, each participant was given a station with computer, VR-headset and controllers for practicing 10-15 min alone in the tool. The participants could then ask questions and receive recommendations on how to use the tool. Afterwards, they read a short script explaining the scene that they should produce in the previs interface. This was done alone before the solo setup and together with another participant before the collaborative setup. After reading the script, the participants wrote down a short statement about their idea on how they would plan and shoot the scene, to be able to compare with their final result afterwards. The participants were then given 15 minutes for the current previs-session and were asked to fill a post-task questionnaire. After this, the groups switched setup, read the script for the second task and then performed the second previs-session accompanied by a post-task questionnaire. After each session, the participants filled out a post-experiment questionnaire.

The main task for the participants was to make a single-shot scene that corresponds to the script that the participants read. No movie-editing was therefore involved for this experiment. The single-shot was supposed to be between 20-30 seconds long and the participants could use as many camera takes as they pleased, but had to choose one take as their final end-resulting clip. 


\subsection{Measures}

At the end of each task in the experiment, participants filled out a post-task questionnaire (see Figure 7) asking them about presence in the virtual environment, the co-presence of other participants (if collaborative condition), their experience of performance and behaviour, and their feeling of their part in the process and the resulting clip. At the end of each experiment, two final questionnaires were employed: a post-experiment questionnaire and a personality questionnaire.

4.5.1 Post-task questionnaires. Questions on the feeling of presence and co-presence were collected from [Gerhard et al. 2007] where Gerhard et al. have extended questions [Witmer and Singer 1998] on involvement and immersion with questions regarding multi-user virtual environments. Presence and co-presence are important measures for this project as they describe how the participants felt about their task in relation to their experienced presence of being in a virtual environment as well as with other participants (co-presence). According to Gerhard et al., immersion has to do with experiencing that a user is present in the VE and is highly connected to the form of the system, presence is similar to this, yet is more of a 'response' to the VE system that is achieved at a certain level of immersion. Involvement relates to the content of the VE, where a user is interested and can loose track of time [Slater 2003].

4.5.2 Post-experiment questionnaire. The post-experiment questionnaire measured participants' previous experience with VR, previous experience with game controllers and their working experience in the film industry. In the question about each participant's experience in VR we expected to find differences between participants with experience compared to those with little or none experience. Likewise, with the question concerning the participant's experience in using controllers typically used in games, we expected to find differences between experience and results. The post-experiment questionnaire also included a set of open-ended questions. These questions provided feedback on where the participants found the most difficulties with the interface and three extra questions encouraged participants to choose and motivate their choice between solo and collaborative on different aspects (see table 2).

4.5.3 Personality questionnaire. Participants' personality traits are extracted from the 10-item Big Five personality [Barrick and Mount 1991] measure. These factors were expected to influence participants' preferences, performance and collaboration patterns.

\section{RESULTS}

In this section, we analyze the results of our three questionnaires. First, we measure the differences between the two different experiment conditions by analyzing the responses from the post-task questionnaires answered directly after each task. Second, the withinsubjects setting demanded that each participant performed each previs condition, hence we asked for direct comparisons and we present both statistical analysis and the subjective opinions from the qualitative and open-ended parts of the assessment. Finally, we analyze whether the participants' personality traits might have effected the responses.

\subsection{Post-task questionnaires}

A repeated measures ANOVA showed two significant trends in our data (see Table 1). In the question How well could you concentrate on the assigned task rather than on the mechanisms used to perform these?, the solo setup received a higher rating than collaborative $(F(1,17.875)=5.979, p<0.05)$. In the same way, the solo setup received a higher rating in How would you rate your performance in this task? $(F(1,19)=6.066, p<0.05$. $)$ The repeated measures ANOVA showed results that were not hypothesized. The initial hypothesis was that the filmmakers would prefer the collaborative setup, as it is more familiar to a real-life scenario where filmmakers collaborate in the production of a film.

The mean values for each question from the questionnaires directly after each experiment can be seen in Figure 7.

\section{Table 1: Significant repeated measures ANOVA}

\begin{tabular}{|c|c|c|c|c|c|}
\hline \multicolumn{6}{|c|}{$\begin{array}{l}\text { How well could you concentrate on the assigned task rather } \\
\text { than on the mechanism used to perform these? }{ }^{*} p<0.05\end{array}$} \\
\hline \multirow[t]{2}{*}{ Source } & & $\mathrm{df}$ & Mean square & $\mathrm{F}$ & Sig. \\
\hline & $\begin{array}{l}\text { Greenhouse- } \\
\text { Geisser }\end{array}$ & 1 & 5.625 & 5.979 & $0.024^{*}$ \\
\hline Error & $\begin{array}{l}\text { Greenhouse- } \\
\text { Geisser }\end{array}$ & 19 & 0.941 & & \\
\hline \multicolumn{6}{|c|}{ How would you rate your performance in this task? } \\
\hline \multirow[t]{2}{*}{ Source } & & $\mathrm{df}$ & Mean square & $\mathrm{F}$ & Sig. \\
\hline & $\begin{array}{l}\text { Greenhouse- } \\
\text { Geisser }\end{array}$ & 1 & 3.025 & 6.066 & $0.024^{*}$ \\
\hline Error & $\begin{array}{l}\text { Greenhouse- } \\
\text { Geisser }\end{array}$ & 19 & 0.499 & & \\
\hline
\end{tabular}

\subsection{Post-experiment questionnaire}

Chi-squared tests were performed to measure the relation between solo and collaborative setup. One of these shows that significantly more participants answered "Collaborative" on the question of Which setup do you think is most useful in an actual pre-production? Why? 17 participants answered the question (3 people answered "Both" and were thus not included in the comparison), where 14 answered collaborative setup and three participants answered solo setup.

$$
\chi^{2}(1, N=17)=14.235, p<0.01
$$

There were no significant results in terms of Which setup was more enjoyable? Why? or Which setup did you prefer? Why? which will be further discussed in section 6 . A second chi-squared test showed that participants also felt familiarity with the role they had during the collaborative setup, to a significant amount.

$$
\chi^{2}(1, N=20)=5.000, p<0.01
$$

5.2.1 Open-ended questionnaire. Regarding the open-ended qualitative comparisons included in the post-experiment questionnaire, these answers were analyzed and coded. After this, a thematic analysis divided and connected codes into themes. The themes that were eligible are those with codes occurring two times or more. The nature of these questions can be divided into two categories: comparison between the two conditions, and design of the interface. The parts regarding conditions can be seen in Table 2, whereas the results regarding design will be further discussed in the discussion section. 


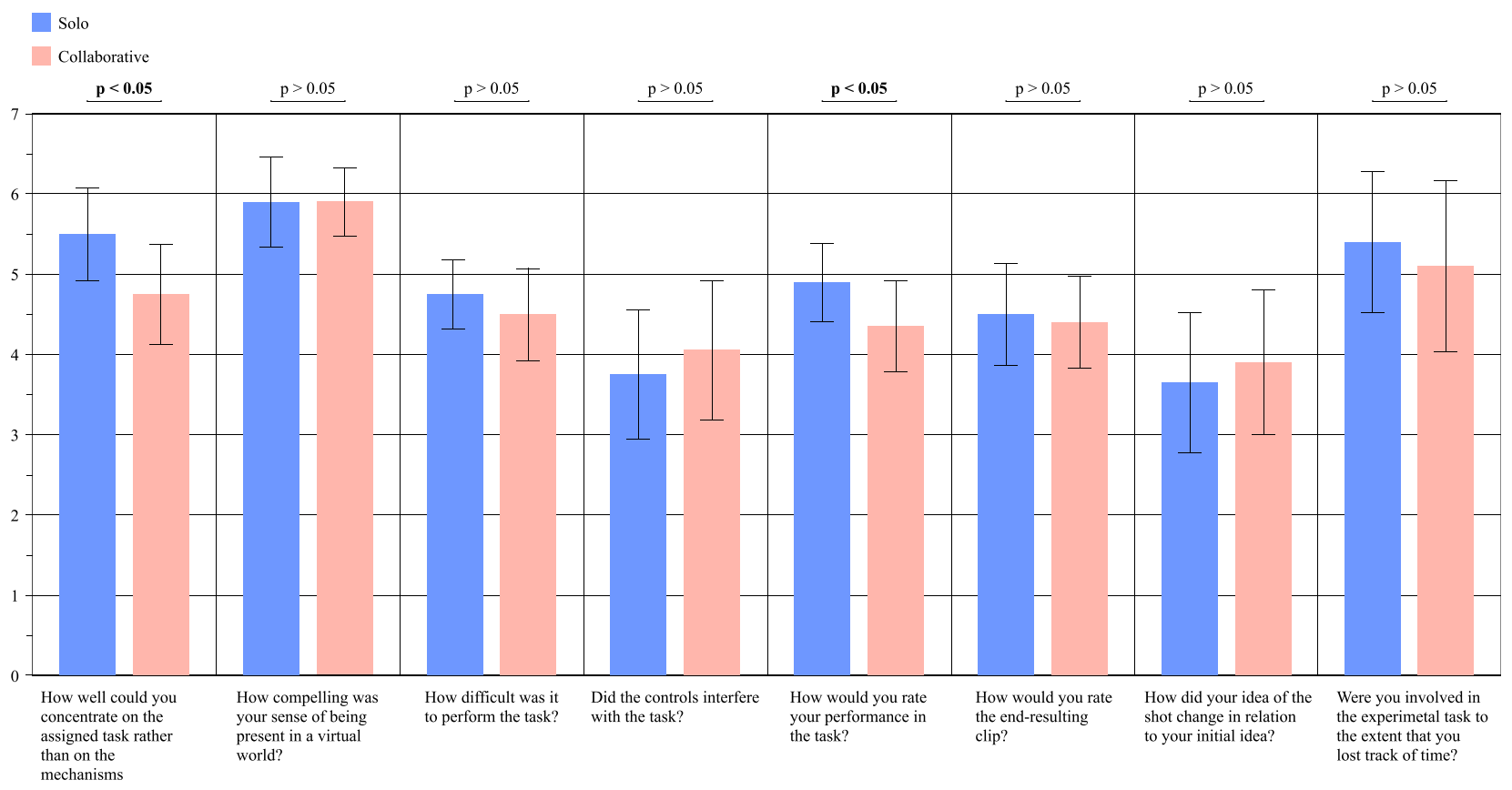

Figure 7: Mean values for each questionnaire question in both setups.

The identified difficulties in the interface design was mainly due to familiarity with the controllers and usability issues with the VR system used in the project:

"One of the bigger challenges were that the picture from the camera got lost inside walls and characters. I wanted it to stay visible the whole time and not move around."

"Move the actor in a constant speed"

"Learning to handle the tools"

"In the beginning learning all functions with the hand controls."

Table 2: Thematic analysis of qualitative results.

\begin{tabular}{|l|l|}
\hline Which setup was more enjoyable? Why? \\
\hline Theme & Occurrences \\
\hline Collaborative & 3 \\
\hline Focus & 4 \\
\hline Fun & 3 \\
\hline Solo & \multicolumn{2}{|l|}{} \\
\hline Focus \\
\hline $\begin{array}{l}\text { Which setup do you think is most useful in an actual pre- } \\
\text { production? Why? }\end{array}$ \\
\hline Collaborative & 7 \\
\hline Communication/work together & 2 \\
\hline Testing & 2 \\
\hline Real-life scenario & 2 \\
\hline Different skills & 2 \\
\hline Tangible & 2 \\
\hline Which setup did you prefer? Why? \\
\hline Collaborative & 3 \\
\hline Creativity & 2 \\
\hline Solo \\
\hline Safe/ no pressure \\
\hline Easier
\end{tabular}

The themes found in the analysis (see Table 2) reflects the occurrences of how many times a theme was mentioned. In the first part, on the question of which setup was more enjoyable, participants mentioned that the focus was superior in the specific setting. These could therefore have been mentioned in both setups, as different participants mentioned focus in different setups. Furthermore, the answers revealed how communication and working together with someone was important, and that the use of different skill sets reminded of a real-life scenario where filmmakers would collaborate, as described by the following quotes:

"[...] it mimics a 'real life' set"

"[...] you can test ideas and impressions"

"[...] you cannot manage all tasks during a real shoot either and when you already start to collaborate in the pre-viz it will be easier to do the real shoot in the end"

As mentioned in the previous subsection, there was a significant effect in how the participants felt like the role they played during the experiments. This was also evident in both the quantitative and the qualitative part.

"I could comment more, like a director would"

"I felt like a director because the dialogue with the photographer was just like on the set"

\subsection{Personality Questionnaire}

Bivariate correlations were performed between the questionnaire responses and the personality traits. The correlations showed significance between the five personality traits and the questionnaire responses. It showed that the correlation between Extraversion and Were you involved in the experimental task to the extent that you lost track of time? was significant (Pearson's correlation: 
Table 3: Significant correlations, personality traits and questionnaire results. ${ }^{*} \mathrm{p}<0.05,{ }^{* *} \mathrm{p}<0.01$

\begin{tabular}{|c|c|c|c|c|c|}
\hline \multirow{3}{*}{$\begin{array}{l}\text { How compel- } \\
\text { ling was your } \\
\text { sense of being } \\
\text { present in a } \\
\text { virtual world? }\end{array}$} & & \multicolumn{2}{|c|}{$\begin{array}{l}\text { Extra- } \\
\text { version }\end{array}$} & $\begin{array}{l}\text { Conscient- } \\
\text { iousness }\end{array}$ & $\begin{array}{l}\text { Opennes } \\
\text { to exp. }\end{array}$ \\
\hline & $\begin{array}{l}\text { Pearson } \\
\text { Corr. }\end{array}$ & \multicolumn{2}{|c|}{0.205} & -0.102 & 0.331 \\
\hline & Sig. & \multicolumn{2}{|c|}{0.205} & 0.53 & $0.037^{*}$ \\
\hline \multirow{2}{*}{$\begin{array}{l}\text { How difficult } \\
\text { was it to } \\
\text { perform } \\
\text { the task? }\end{array}$} & $\begin{array}{l}\text { Pearson } \\
\text { Corr. }\end{array}$ & \multicolumn{2}{|c|}{0.033} & 0.205 & -0.353 \\
\hline & Sig. & \multicolumn{2}{|c|}{0.839} & 0.204 & $0.026^{*}$ \\
\hline \multirow{2}{*}{$\begin{array}{l}\text { How would } \\
\text { you rate your } \\
\text { performance } \\
\text { in this task? }\end{array}$} & $\begin{array}{l}\text { Pearson } \\
\text { Corr. }\end{array}$ & \multicolumn{2}{|c|}{0.154} & 0.324 & 0.221 \\
\hline & Sig. & \multicolumn{2}{|c|}{0.342} & $0.041^{*}$ & 0.171 \\
\hline \multirow[t]{2}{*}{$\begin{array}{l}\text { Were you in- } \\
\text { volved in the } \\
\text { experimental } \\
\text { task to the ex- } \\
\text { tent that you } \\
\text { lost track } \\
\text { of time? }\end{array}$} & $\begin{array}{l}\text { Pearson } \\
\text { Corr. }\end{array}$ & \multicolumn{2}{|c|}{0.372} & -0.446 & 0.042 \\
\hline & Sig. & & $0.018^{\mid x}$ & $0.004^{* *}$ & 0.796 \\
\hline \multirow[t]{2}{*}{$\begin{array}{l}\text { I was aware of } \\
\text { the actions of } \\
\text { other partici- } \\
\text { pants }\end{array}$} & \multicolumn{2}{|c|}{$\begin{array}{l}\text { Pearson } \\
\text { Corr. }\end{array}$} & -0.019 & 0.196 & 0.599 \\
\hline & \multicolumn{2}{|l|}{ Sig. } & 0.935 & 0.407 & $0.005^{* \star}$ \\
\hline \multirow[t]{2}{*}{$\begin{array}{l}\text { Which setup } \\
\text { was more } \\
\text { enjoyable? }\end{array}$} & \multicolumn{2}{|c|}{$\begin{array}{l}\text { Pearson } \\
\text { Corr. }\end{array}$} & 0.473 & -0.154 & 0.293 \\
\hline & \multicolumn{2}{|l|}{ Sig. } & $0.005^{2 \pi}$ & 0.383 & 0.092 \\
\hline \multirow[t]{2}{*}{$\begin{array}{l}\text { Which setup } \\
\text { did you prefer? }\end{array}$} & \multicolumn{2}{|c|}{$\begin{array}{l}\text { Pearson } \\
\text { Corr. }\end{array}$} & 0.442 & -0.236 & -0.128 \\
\hline & \multicolumn{2}{|c|}{ Sig. } & $0.009^{* *}$ & 0.178 & 0.47 \\
\hline
\end{tabular}

$0.372, p<0.05$.) Likewise, Extraversion together with Which setup did you prefer? and Extraversion together with Which setup was more enjoyable? showed a significant result (Pearson's correlation: $0.442, p<0.01$, Pearson's correlation: $0.473, p<0.01$ ).

Furthermore, Openness to new experiences correlated on a significant level with How compelling was your sense of being present in a virtual world? (Pearson's correlation: $0.331, p<0.05$ ), How difficult was it to perform the task? (Pearson's correlation: 0.353, $p<0.05$ ), and I was aware of the actions of other participants (Pearson's correlation: $0.599, p<0.01)$.

\section{DISCUSSION}

The results presented above appear to confirm our hypotheses that VR technologies can be used successfully for remote collaboration in previsualization. In our experiment, participants ruled the collaborative setup to be more useful in a real-life pre-production scenario. The participants mentioned the use of different skills and the relation to a familiar real-life scenario where working together is a standard part of filmmaking as reasons for the usefulness of the tool. However, we also expected that the collaborative condition would be more enjoyable and preferable (Which setup was more enjoyable? Why?, Which setup did you prefer? Why?). We did not find support for this, as no significant differences were found, and the participants found it slightly more enjoyable in the solo condition, and marginally preferred this condition. An explanation for these results can be found by looking at the the repeated measures ANOVA (Table 1), where we found that the concentration level and how each participant rated their performance showed significantly higher results for the solo condition. This is also something that was not expected yet showed interesting trends. Some of these results are properly illustrated by the comments from the participants:

"[T] he one where I was alone was a bit more enjoyable since I could focus solely on how I wanted the scene and how I could perform. But the interactiveness of being two people in the same VR-scene collaborating was a new and very fun experience which I think, given more time would give a better end result."

"Since I did the single (solo) part last I preferred that one. I felt most secure then."

\subsection{Interface}

It is evident from the results that feeling in control of the tool and its components had impacts on the participants' experience. The interface design and the collaborative aspects of working in this particular virtual environment are thus connected. The participants thought the tool would be useful in a real-life scenario, to a significant level, whereas a small majority of the participants enjoyed and preferred the solo condition. This is somewhat contradictory, as one could assume that professional filmmakers would enjoy a situation similar to a real-life scenario more. It can be argued that the reason for why some participants enjoyed and preferred the solo condition to a slightly higher extent could have been due to several effects: how well the participants knew each other? did they previously worked together in a similar situation? which condition the participant started out with? how they compared themselves with other participants during the collaborative condition?

Having someone else present in the creative work could have made some of the participants less likely to rate their performance high, as they may feel judged by the other participant. On the other hand, this could also be related to the way the interface design was built, where the role of director did not have the same controls as the photographer and was thus more limited in the functionality that could be accessed. It can be argued that this fact could induce the participants to feel more secure and free in the solo setup, thus rating that one higher in regard to their own performance and preference. Also, some directors complained about not having a monitor and tried to stand behind the photographer to see the image. This caused limitations in the collaborative work. Other participants used our intended solution to solve this problem and teleported to the cinema room so they could collaboratively see the image in real-time.

In both tasks, the question How compelling was your sense of being present in a virtual world? scored 5.9 on the 7-point Likert scale, as can be seen in Table 7. This highlights how the design of the interface was successful in the participants' feeling a high sense of presence in the virtual environment. The affordances of VR should mimic the real world as much as possible, as mentioned in [Ellis 1995]. Our results clearly show that this was the case by observing the ratings of how the participants were involved to the extent 
that they lost track of time to a high extent (solo: 5.4, collaborative: 5.1). Furthermore, after the collaborative setup, the questionnaire statement I was aware of the actions of the other participants received a result of 5.95, further highlighting that the interface did in fact reflect a real world scenario where filmmakers collaborate with other colleagues. Furthermore, the representation of other participants with avatars and audio feedback of voice made the communicative aspect of the collaboration successful. A majority of the participants could find grounding in their communication early on in the collaborative experimental setup, where most participants initiated discussions to make creative decisions immediately.

The amount of training that the participants got before the experiments could have been longer to obtain the full potential of the participants' work. According to one participant, having about an hour of training would probably make the interface more usable. The training session lasted for 10-15 min during the experiments, and the participants did learn the controls and functionality in different places. Thus, if a participant started out in the collaborative setup with the role of director, the training would include functionality that the experiment did not. These functionalities would come back to the participant during his/her solo session. However, this opinion was not shared by most participants and can therefore not be assumed to be a significant cause.

"The second one (solo setup) because I had got better grip on the technique the second time."

"[...] the last one (solo setup), when I had more experience"

Moreover, the above mentioned quotes points out that order had some effect on their perceived performance and experience. Several participants mentioned that the collaborative condition was easier to perform in if the solo condition had been performed first.

Lastly, the main difficulties mentioned from the qualitative results points to the controls and usability issues with the HTC Vive, highlighting that further improvements to the interface should focus on usability issues rather than on the communicative and collaborative aspects of the interface design.

\subsection{Insights on the Design}

The current design had some flaws and benefits that can guide future previsualization VR solutions on how to best design their system and on how to avoid pitfalls. First and foremost, the decision to divide the user interface between different roles had benefits for the collaborative aspects, as participants felt as their role, to a significant level. However, it also showed some negative effects as some participants mentioned that they felt limited when working as the role of director. The effect of order and the different personality traits did also show some effects as a few participants mentioned that they preferred the second task because they had more experience in the tool. Therefore, pin-pointing a universal design for this kind of collaborative interface is complex.

Nevertheless, it was evident that communication and grounding is crucial for collaborative environments. These include visual and audio feedback of other users present in the virtual environment, e.g. avatars as representation of other users. Furthermore, the usecase of the VR application plays an important role. In this project, the use-case was clearly defined as a previsualization tool primarily made for filmmakers. Thus, the intended users had knowledge-incommon that helped them understand the task and make it clear for them how to work creatively in the tool. Therefore, collaborative VR applications should have clearly defined users where the virtual environment reflects the knowledge-in-common of the users. To provide a collaborative context, the need to coordinate the tasks becomes more simple when the users have this shared familiar knowledge that is present among people in a specific discipline or working context.

Another important aspect is the shared visual information. As described in the related literature, having shared visual information is crucial for providing grounding which furthermore provides a foundation for communication and collaboration.

\subsection{Big Five Personality Traits}

Some of the results that show disadvantages of the collaborative setup when compared to solo had to do with personality traits: the higher the score within extraversion, the more enjoyable the collaborative setup scored. The collaborative setup was more preferred by extroverted people. The significance of extraverted people enjoying and preferring a collaborative setup was not surprising, as extraverted people can be assumed to be more interested in being with other people. This was an expected result and the main reason for why the personality questionnaire was included.

\section{CONCLUSIONS}

VR applications are becoming more advanced and are finding their way into more peoples' lives. The use-cases of VR applications are expanding and filmmakers can benefit from these technologies. Previsualization is an important part of pre-production that can help with the planning of scenes and takes in a cost-friendly way.

Our results indicate that the tool proposed in this paper is useful for real-life previs, where filmmakers can discuss, edit, and validate different camera works and character movements. The participants in our study provided positive feedback in terms of sense of presence, immersion, involvement in the task and the collaborative aspects of working together with another co-worker in a virtual environment.

In regard to the usefulness of VR technologies for previsualization of the proposed tool, the results were positive due to the participants prior knowledge about pre-production and filmmaking, where the ability to test and discuss different aspects of takes and scenes were amongst the most important remarked aspects. By including elements for finding grounding in the collaborative work, such as shared visual context, speech communication and awareness of the other participant, the scenario was familiar to the participants. VR has the affordances of bringing these factors together because the participants could focus on the task at hand rather than on the mechanisms surrounding the VR system to a high extent. As described earlier, there are still some usability issues that require further work. The insights obtained for collaborative VR applications within filmmaking show that making use of the knowledge-in-common among a specific set of users and enhancing this shared knowledge is important for providing a tool that can be perceived as serious and useful for real-life scenarios. Also, the 
advantages of using VR for remote collaboration showed that the location of other co-workers did not affect the feeling of co-presence and the immersive qualities of VR made the participants feel like they were in the actual scene and thus having a sense of being in a familiar task setting/scenario.

\section{ACKNOWLEDGEMENTS}

This work was supported by the collaboration between the Royal Institute of Technology and Stockholm Academy for Dramatic Arts. We would also like to thank Andreas Dahn for providing the resources and assets for the experiment scenario.

\section{REFERENCES}

Christoph Anthes, Rubén Jesús García-Hernández, Markus Wiedemann, and Dieter Kranzlmüller. 2016. State of the art of virtual reality technology. In IEEE Aerospace Conference Proceedings. https://doi.org/10.1109/AERO.2016.7500674

Murray R. Barrick and Michael K. Mount. 1991. The Big Five Personality Dimensions And Job Performance: A Meta-Analysis. Personnel Psychology 44, 1 (1991), 1âĂŞ26. https://doi.org/10.1111/j.1744-6570.1991.tb00688.x

Scott Bateman, Anthony Tang, Brennan Jones, Carman Neustaedter, and Anna Witcraft. 2015. Mechanics of Camera Work in Mobile Video Collaboration. https://doi.org/ $10.1145 / 2702123.2702345$

John M. Carroll, Mary Beth Rosson, Gregorio Convertino, and Craig H. Ganoe. 2006 Awareness and teamwork in computer-supported collaborations. Interacting with Computers (2006). https://doi.org/10.1016/j.intcom.2005.05.005

Tommas Celata, Antonio Notarangelo, Laura Anna Ripamonti, Davide Gadia, and Dario Maggiorini. 2018. G.E.M.I.X.: Game Engine Movie Interaction eXperience. In CEUR Workshop Proceedings.

Herbert H. Clark and Susan E. Brennan. 2004. Grounding in communication. In Perspectives on socially shared cognition. https://doi.org/10.1037/10096-006

Stephen R Ellis. 1995. Simulated and Virtual Realities: Elements of Perception.

Carmine Elvezio, Frank Ling, Jen-Shuo Liu, and Steven Feiner. 2018. Collaborative Virtual Reality for Low-Latency Interaction. https://doi.org/10.1145/3266037.3271643

Jamie Feltham. 2018. Nvidia Predicts 50 Million VR Headsets Sold By 2021. https: //uploadvr.com/nvidia-predicts-50-million-vr-headsets-sold-2021/

Susan R Fussell, Robert E Kraut, and Jane Siegel. 2000. Coordination of Communication : Effects of Shared Visual Context on Collaborative Work. In CSCW. https://doi org $/ 10.1145 / 358916.358947$

Susan R. Fussell, Leslie D. Setlock, and Robert E. Kraut. 2003. Effects of head-mounted and scene-oriented video systems on remote collaboration on physical tasks. https: //doi.org/10.1145/642700.642701

Darren Gergle. 2005. The value of shared visual space for collaborative physical tasks. https://doi.org/10.1145/1056808.1056839

Darren Gergle, Robert E. Kraut, and Susan R. Fussell. 2005. Action as language in a shared visual space. https://doi.org/10.1145/1031607.1031687

M. Gerhard, D. J. Moore, and D. J. Hobbs. 2007. Continuous Presence in Collaborative Virtual Environments: Towards a Hybrid Avatar-Agent Model for User Representation. https://doi.org/10.1007/3-540-44812-8_12

Eve Light Honthaner. 2017. The Complete Film Production Handbook. https://doi.org/ 10.4324/9780080884998

Ryosuke Ichikari, Keisuke Kawano, Asako Kimura, Fumihisa Shibata, and Hideyuki Tamura. 2007. Mixed reality pre-visualization and camera-work authoring in filmmaking. In Proceedings - ISMAR 2006: Fifth IEEE and ACM International Symposium on Mixed and Augmented Reality. https://doi.org/10.1109/ISMAR.2006.297823

Linda Janson. 2019. Interview with professional scenographer about pre-production in film making.

Steven Johnson, Madeleine Gibson, and Bilge Mutlu. 2015. Handheld or Handsfree? Remote Collaboration via Lightweight Head-Mounted Displays and Handheld Devices. In CSCW. https://doi.org/10.1145/2675133.2675176

Muhammad Sikandar Lal Khan, Haibo Li, and Shafiq ur Réhman. 2016. Tele-Immersion: Virtual Reality Based Collaboration. In HCI International 2016: Posters' Extended Abstracts : 18th International Conference, HCI International 2016. Springer, Toronto, 352-357. https://doi.org/10.1007/978-3-319-40548-3_59

Philipp Ladwig and Christian Geiger. 2018. A Literature Review on Collaboration in Mixed Reality. In 15th International Conference on Remote Engineering and Virtual Instrumentation.

Shohei Mori, Ryosuke Ichikari, Fumihisa Shibata, Asako Kimura, and Hideyuki Tamura. 2011. Enabling on-set stereoscopic MR-based previsualization for 3D filmmaking. In SIGGRAPH Asia 2011 Sketches, SA'11. https://doi.org/10.1145/2077378.2077396

Thomas Muender. 2018. Empowering Creative People : Virtual Reality for Previsualization. Extended Abstracts of the 2018 CHI Conference on Human Factors in Computing Systems (2018). https://doi.org/10.1145/3170427.3188612
Michael Nitsche. 2009. Experiments in the use of game technology for pre-visualization. https://doi.org/10.1145/1496984.1497011

Tekla S. Perry. 2015. Virtual reality goes social. IEEE Spectrum (2015). https://doi.org/ 10.1109/mspec.2016.7367470

Kevin Pfeil, Eugene M Taranta, Arun Kulshreshth, Pamela Wisniewski, and Joseph J Laviola. 2018. A Comparison of Eye-Head Coordination Between Virtual and Physical Realities. (2018). https://doi.org/10.1145/3225153.3225157

Thammathip Piumsomboon, Youngho Lee, Gun A. Lee, and Mark Billinghurst. 2016. CoVAR: a collaborative virtual and augmented reality system for remote collaboration. In American Economic Review. https://doi.org/10.1257/aer.20120555 arXiv:-

Joshua Ramsbottom. 2015. A Virtual Reality Interface for Previsualization. Ph.D. Dissertation. University of Cape Town. https://people.cs.uct.ac.za/\{ $\}$ previz2015/ virtual-reality/vr-report.pdf

Hanieh Shakeri, Samarth Singhal, Rui Pan, Carman Neustaedter, and Anthony Tang. 2017. Escaping Together: The Design and Evaluation of a Distributed Real-Life Escape Room. Proceedings of the Annual Symposium on Computer-Human Interaction in Play - CHI PLAY '17 (2017). https://doi.org/10.1145/3116595.3116601

Mel Slater. 2003. A Note on Presence Terminology. Presence Connect 3 (01 2003).

Simon Spielmann, Andreas Schuster, Kai Götz, and Volker Helzle. 2016. VPET: a toolset for collaborative virtual filmmaking. In SIGGRAPH ASIA 2016 Technical Briefs. ACM, 29.

H. Tenmoku, R. and Ichikari, R. and Shibata, F. and Kimura, A. and Tamura. 2006. Design and prototype implementation of MR pre-visualization workflow. In Proc. Int. Workshop on Mixed Reality Technology for Filmmaking.

Bob G. Witmer and Michael J. Singer. 1998. Measuring presence in virtual environments: A presence questionnaire. Presence: Teleoperators and Virtual Environments (1998). https://doi.org/10.1162/105474698565686 